\title{
Visual-Sensory-Based Quiet Room for Reducing Maladaptive Behavior and Emotion in Autistic Individuals: A Review
}

\author{
* $1^{\text {st }}$ Annisa Marwati \\ Department of Architecture, Faculty of \\ Engineering \\ Universitas Indonesia \\ Depok, Indonesia \\ annisa.marwati71@ui.ac.id
}

\author{
$2^{\text {nd }}$ Ova Candra Dewi \\ Department of Architecture, Faculty of \\ Engineering \\ Universitas Indonesia \\ Depok, Indonesia \\ ova.candewi@ui.ac.id
}

\author{
$3^{\text {rd }}$ Tjhin Wiguna \\ Department of Psychiatry, Faculty of \\ Medicine \\ Universitas Indonesia \\ Jakarta, Indonesia \\ tjin.wiguna@ui.ac.id
}

\begin{abstract}
This paper proposes the idea of optimizing visual sensory comfort in a quiet room for autistic users. Previous studies had proved that most individuals with autism spectrum disorder have unique sensory sensitivity and may perceive sensory stimulation differently. Maladaptive behavior and emotion are often shown by autistic individuals due to sensory discomfort, which leads them to have more difficulties in daily activities. This paper argues that visual-sensory-based design intervention for a quiet room has the potential to reduce maladaptive behavior and emotion in individuals with an autism spectrum disorder. The design interventions were developed by reviewing several studies about visual comfort in general, visual comfort for autistic users, and the quiet room itself. This review emphasized three aspects of strategies for an effective visual-sensory-based quiet room; (1) accommodating the most possible visual comfort for autistic users, (2) providing the calming function of the quiet room itself, and (3) ensuring safety by minimizing physical hazard in the room. A list of visual-sensory-based intervention strategies for autistic users is provided as a result. The strategies are not only focused on visual comfort for autistic users, but also the functionality and security factors of the quiet room. As a conclusion, adjusting a quiet room with visual-sensory-based design intervention is expected to be able to help autistic users in releasing the occurring maladaptive behavior and emotion, especially while they are in a stressful environment such as school or other crowded public space. Moreover, reduced disturbing behavior and emotion may give individuals with autism spectrum disorder more opportunity to live and grow to their maximum potential.
\end{abstract}

Keywords-Quiet Room, Visual Sensory Comfort, Autism Spectrum Disorder, Architectural Intervention, Maladaptive Behavior and Emotion

\section{INTRODUCTION}

Autism Spectrum Disorder (ASD) is a neurodevelopmental disorder that causes several unusual behaviors [1]. According to Gilberg \& Coleman (2000), Autism Spectrum Disorder impacted someone's ability to communicate and interact socially [2]. A study by Konst et al. (2013) shows that Maladaptive behavior such as temper tantrums and aggression are common in individuals with ASD [3]. Maladaptive behavior, which may escalate along with the increasing of negative emotion [4], has strong correlations with sensory processing issues [3]. Meanwhile, it is believed that around $69 \%$ to $93 \%$ of individuals with autism spectrum disorder have sensory issues, both on children or adults [5]. Sensory Processing Disorder (SPD) is a condition that causes someone's inability to process information sent from the sensory senses [6]. According to Kelly Dorfman's sensory processing disorder continuum graphs, individuals with autism spectrum disorder mostly have severe conditions of sensory processing disorder [6]. Someone may be overly reactive to certain stimulation (hypersensitive), less reactive (hypo sensitive), showing sensory-seeking behavior, or other fluctuating reactions [6].

Therefore, providing the right sensory stimulation in the environment for autistic users is important to prevent them from showing disturbing behavior or emotion. Unfortunately, in certain places like public spaces, the right stimulus settings might be hard to implement. Providing a quiet room with sensory comfort qualities may be a solution to help autistic individuals release maladaptive behavior and emotion sooner rather than later.

\section{VISUAL-SENSORY-BASED QUIET ROOM PARAMETERS}

A visual-sensory-based quiet room is not dependent only on its visual comfort quality. As a quiet room, its functionality and safety aspects are equally important. The calming function of a quiet room is developed through previous theories that discussed a quiet room or an escape space. Meanwhile, the safety aspect is suggested as autistic users may show self-harming behavior in a certain situation. Figure 1 shows the parameters of visual-sensory-based.

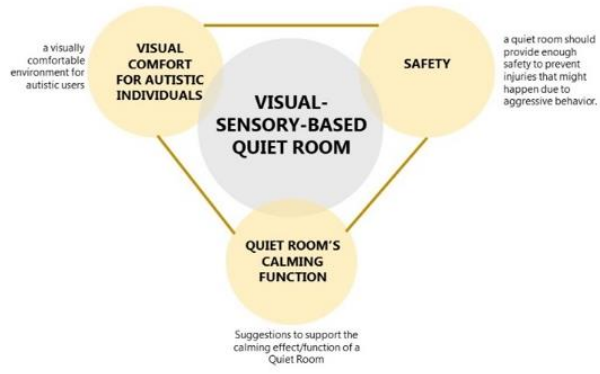

Fig. 1. Visual-Sensory-Based Quiet Room Parameters 


\section{VISUAL COMFORT FOR AUTISTIC USERS}

Four factors affect the suitability of lighting. They are color appearance and color rendering, a color appearance that is associated with mood and the expected 'atmosphere', the directionality of light, and glare [9]. According to these factors, there are at least three key points that affect visual input namely lighting, glare, and color.

\section{A. Lighting and Glare for Autistic users}

The settings for light reflection, glare, and shadow are important in a room for autistic users [10]. Glare is caused by overly-high saturated light that may cause visual discomfort. Glare has to be avoided because it may cause not only overstimulation [8], [11], [12] but also lead to distress and anxiety in autistic users [13]. There are two types of glare, indirect (reflected) glare and direct glare [14]. Closer distance to the lighting source will increase the probability of glare. Lighting and glare in a room can come from two sources; natural and electrical lighting.

Although the effectivity of natural lighting in a room for autistic users has been a debate [15], it has been proved that natural lighting is beneficial for individuals with autism spectrum disorder [11]. Natural lighting may improve academic performance [8], [16], concentration, relax eye pupils, and also decrease hyperactivity [16]. Nonetheless, the glare from natural lighting should also be avoided. The use of indirect natural lighting [17], shades [10], and not putting a source of light at an eye-level may be options to avoid glare [18]. Moreover, natural lighting from the Southside is more recommended, and the choice of color for wall painting near the window is also important to avoid glare.

For electrical lighting usage, fluorescent lamps are not recommended because of their flickering effect which may lead autistic users to show disturbing reactions [11]. Additionally, the cool-colored temperature in fluorescent lighting may lead to frustrating situations [18]. A study proved that the replacement of fluorescent lamps with halogen lamps can improve the students with an autism spectrum disorder to pay more attention to the class and be more focused [19]. Warm colored lamps such as incandescent lamps are more suggested, even though they are less durable and efficient [18]. To get the energy efficiency as well as the visual comfort for autistic users, the use of LED light with a warm color temperature may be a better choice. LED lamps have the longest durability with the lowest energy consumption [14]. LED lamps use only 10\%$20 \%$ of the energy needed by the incandescent lamps to perform the same light intensity [9]. Moreover, to control glare from electrical lighting, it is important to install dimmer control [11], add lamp diffusers around the lamp, and set the light with an indirect setting [14].

\section{B. Color}

Color is a design element which may give psychological effects, including mood-changing effect [20]. Color can be recognized by the human body not only through visual senses but also through the skin by the absorption of the color wave[20]. The colors that have a calming and relaxing effect are green and blue [21]. This is supported by Logan Clarke and Appleby (2009) who stated that the green color may help in reducing stress, and the blue color may give calming, relaxing, and curing effect [22]. For autistic users, the use of calming, muted color, and the non-patterned wall is more effective for their learning environment [11]. A room with excessive visual stimulation will potentially give distraction to autistic users which may lead to cause difficulties to focus.

\section{QUIET ROOM}

A quiet room or some may refer to it as "Escape Space", is one of the important design aspects in a learning environment for individuals with autism spectrum disorder [10], [11], [23]. "Escape Space" is a space that is intended as a 'relief' space when there is too much stimulation exposed in an environment [11], [23]. Another study has defined a quiet room as a room that provides a "calming effect" when autistic children show disturbing behavior caused by exhaustion, distressing feeling, and overstimulation [10].

In a learning environment, as an escape space, a quiet room should be separated by a partition, located in a quiet section of a room, or quiet corners in several places in a building [23]. Other study mentioned that a quiet room can be located separately, but still not far from the classroom [10], [24]. The quiet room should be as distraction-free as possible, but it may also provide sensory stimulation which can be controlled [11]. Various things with different sensory stimulations such as textured cushions, brush, small tent, blanket, fiber optic lights, headphones, and also aromatherapy oil may be included [23]. Moreover, a Quiet room or Escape Space may look like a mini Snoezelen Curriculum Room [23].

\section{SAFETY}

In creating space for autistic users, the safety aspect is crucially important since they have less awareness of danger and often show unexpected behavior [11]. Safety is mentioned as the most important concern in planning space for autistic students [11]. A room should not allow individuals with an autism spectrum disorder to harm their selves or others [10]. Physical hazards such as sharp edges and corners in a room are the example of safety consideration [23]. Considering its function to release maladaptive behavior, a quiet room should provide enough safety to prevent injuries that might happen due to aggressive behavior.

\section{VISUAL-SENSORY-BASED QUIET ROOM}

This review emphasized three aspects of strategies for a visual-sensory-based quiet room; (1) accommodating the most possible visual comfort for autistic users, (2) providing the calming function of the quiet room itself, and (3) ensuring safety by avoiding physical hazard in the room. The lists of strategies for Visual-Sensory-Based Quiet Room are concluded in Table 1. 
TABLE I. VISUAL-SENSORY-BASED QUIET ROOM DESIGN INTERVENTION STRATEGIES

\begin{tabular}{|c|c|}
\hline Aspects & Strategies \\
\hline $\begin{array}{l}\text { Visual Comfort for } \\
\text { Autistic Users }\end{array}$ & 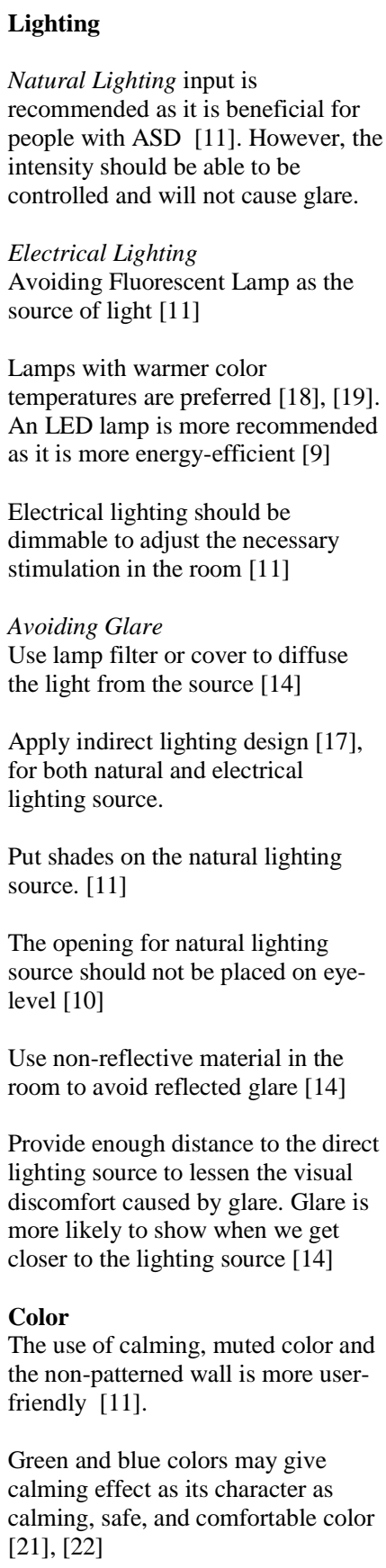 \\
\hline $\begin{array}{l}\text { Suggestions for } \\
\text { supporting the calming } \\
\text { function of a Quiet Room }\end{array}$ & $\begin{array}{l}\text { The quiet room should be separated } \\
\text { by a partition, located in a quiet } \\
\text { section of a room, or the form of } \\
\text { quiet corners in several places in a } \\
\text { building [23]. } \\
\text { The quiet room should provide } \\
\text { minimum or adaptable sensory } \\
\text { stimulation that can meet the needs } \\
\text { of individual users [11]. Dividing } \\
\text { the space into several stimulation } \\
\text { zones, or adding adjustable sensory } \\
\text { equipment can be considered. } \\
\text { Acoustically separated [10], [24]. }\end{array}$ \\
\hline
\end{tabular}

\begin{tabular}{|l|l|}
\hline Aspects & Strategies \\
\hline \multirow{5}{*}{$\begin{array}{l}\text { Equipped with various sensory } \\
\text { stimulation such as cushions, brush, } \\
\text { small tent, blanket, fiber optic lights, } \\
\text { headphones, and aromatherapy oil } \\
{[23] \text { (optional) }}\end{array}$} \\
$\begin{array}{l}\text { Since the size of a room can cause } \\
\text { fear in children with autism [25], the } \\
\text { room size should not be oversized or } \\
\text { undersized. }\end{array}$ \\
\hline Safety & $\begin{array}{l}\text { Space for autistic users should ensure } \\
\text { safety for them, not potentially cause } \\
\text { harm for their selves or the others } \\
{[11]}\end{array}$ \\
\hline
\end{tabular}

The visual comfort design intervention strategies vary from interventions for natural to electrical lighting sources. The Calming function of a quiet room can be supported by separating the room with partition, or even better if it is also acoustically separated from other rooms. Sensory equipment that can be adjusted to the user's sensory needs is also suggested to be added to the room. The equipment can vary from (but not limited to) cushions with a different texture, to a tent which will give low stimulus area within the room. Safety aspects are also needed to be considered since maladaptive behavior is sometimes unpredictable and may lead to a harming situation. The objects in the room should not potentially cause harm to the users or the other people around them.

In short, the visual-sensory-based quiet room is a room which has:

- visual comfort for autistic users; the room should be free from glare, with warmed color temperature electrical lighting, and calming muted color atmosphere,

- minimum sensory stimulation, especially for nonvisual sensory stimulation,

- separated and partitioned area from rooms with other functions,

- adjustable or adaptable sensory stimulation to meet the user's individual need,

- enough safety to respond to the user's possible aggressive behavior that may cause self-harm.

Figure 2 shows the examples of a visual-sensory-based quiet room. 


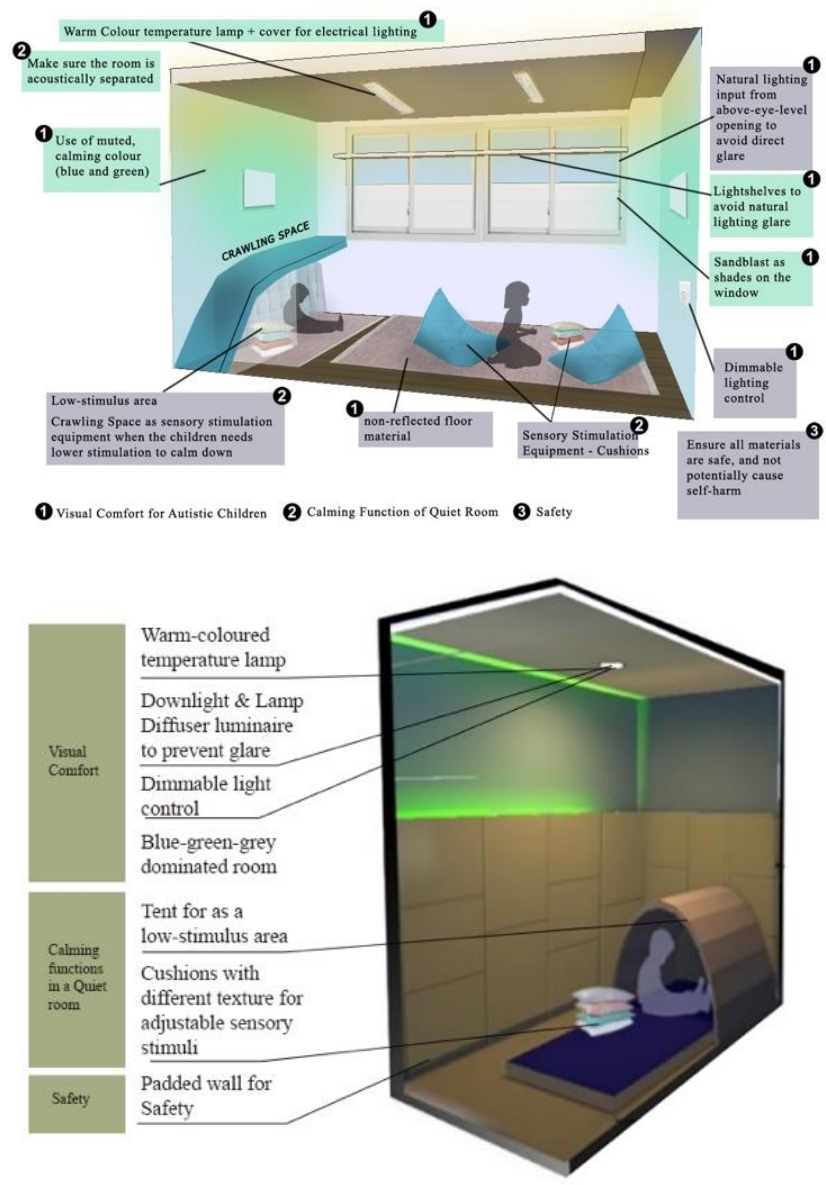

Fig. 2. Examples of Visual-Sensory-Based Quiet Room

\section{CONCLUSION}

The Sensory issue in individuals with autism spectrum disorder is sometimes hard to understand, but it is how they see and perceive the environment differently. When they experience certain sensory discomfort, their reactions may also be different and maladaptive. Maladaptive behavior and emotion can be disturbing as it will affect their activities. As not all places such as schools (especially inclusive schools) or other public spaces like airports and recreational parks can adjust sensory comfort for autistic users, a quiet room is encouraged to be provided. The Visual-Sensory-Based Quiet room can be an architectural intervention to help the autistic individuals to gain back the sensory comfort they need so that they can retreat and unwind. The Visual-Sensory-Based quiet room is a room that considers the optimization of visual comfort for autistic users, the calming function for a quiet room, and the room's safety aspect. However, the effectivity of visual-sensory-based quiet room in reducing maladaptive behavior and emotion in autistic users still needs to be tested for further research. It is hoped that this paper can be a reference in arranging a quiet room, not to mention bringing more awareness of sensory discomfort that often experienced by autistic individuals.

\section{ACKNOWLEDGMENT}

This research is part of a project entitled "Visual-Based Quiet Room for Autistic Children" which is funded by Directorate of Innovation and Science Techno Park
Universitas Indonesia (DISTP-UI) through the Prototype Planning Funding Program 2020 (Hibah Kompetensi Program Pendanaan Perancangan Pengembangan Purwarupa Tahun 2020) No. PKS-25/UN2.INV/HKP.05/2020.

\section{REFERENCES}

[1] R. I. Ismail, T. Wiguna, N. Sw, and F. Kaligis, "Buku Panduan Deteksi Dini Diagnosis Dan Tata Laksana Gangguan Spektrum Autisme," 000122418, 2018.

[2] H. A. E. R. Barakat, A. Bakr, and Z. El-Sayad, "Nature as a healer for autistic children," Alexandria Eng. J., vol. 58, no. 1, pp. 353-366, Mar. 2019.

[3] A. E. Lane, R. L. Young, A. E. Z. Baker, and M. T. Angley, "Sensory processing subtypes in autism: Association with adaptive behavior," J. Autism Dev. Disord., vol. 40, no. 1, pp. 112-122, 2010.

[4] A. C. Samson, A. Y. Hardan, I. A. Lee, J. M. Phillips, and J. J. Gross, "Maladaptive Behavior in Autism Spectrum Disorder: The Role of Emotion Experience and Emotion Regulation," J. Autism Dev. Disord., vol. 45, no. 11, pp. 3424-3432, 2015.

[5] C. McCormick, S. Hepburn, G. S. Young, and S. J. Rogers, "Sensory symptoms in children with autism spectrum disorder, other developmental disorders and typical development: A longitudinal study," SAGE Gloss. Soc. Behav. Sci., vol. 20, no. 5, pp. 572-579, 2016.

[6] C. S. Kranowitz, The Out-of-Sync Child, 2nd ed. New York: Skylight Press/ Perigee, 2005.

[7] C. R. Stewart et al., "Sensory Symptoms and Processing of Nonverbal Auditory and Visual Stimuli in Children with Autism Spectrum Disorder," J. Autism Dev. Disord., vol. 46, no. 5, pp. 1590-1601, 2016.

[8] G. Shabha and K. Gaines, "A comparative analysis of transatlantic design interventions for therapeutically enhanced learning environments - Texas vs West Midlands," Facilities, vol. 31, no. 13, pp. 634-658, 2013.

[9] S. V Szokolay, Introduction to Architectural Science: The Basis of Sustainable Design. Oxford: Architectural Press, 2004.

[10] R. Ghazali, S. R. M. Sakip, and I. Samsuddin, "A Review of Sensory Design Physical Learning Environment for Autism Centre in Malaysia," Environ. Proc. J., vol. 3, no. 7, Feb. 2018.

[11] U. Altenmüller-Lewis, "Designing Schools for Students on the Spectrum,” Des. J., vol. 20, no. sup1, pp. S2215-S2229, Jul. 2017.

[12] P. A. Sánchez, F. S. Vázquez, and L. A. Serrano, "Autism and the Built Environment," in Autism Spectrum Disorders - From Genes to Environment, P. T. Williams, Ed. InTech, 2011, pp. 363-380.

[13] R. Ghazali, S. R. Md. Sakip, and I. Samsuddin, "The Effects of Sensory Design on Autistic Children,” Asian J. Behav. Stud., vol. 3, no. 14 , p. 68 , Nov. 2018.

[14] N. Lechner, Heating, Cooling, Lighting; Sustainable Design Methods for Architects. New Jersey: John Wiley \& Sons, Inc., 2015.

[15] C. N. Henry, "Designing for Autism: Lighting," 2011. [Online]. Available: https://www.archdaily.com/177293/designing-for-autismlighting.

[16] D. P. Leestma, "Designing for the spectrum: An educational model for the autistic user," University of Maryland, 2015.

[17] M. Mostafa, "An Architecture for Autism: Concepts of Design Intervention for the autistic user," Int. J. Archit. Res., vol. 2, no. 1, pp. 189-211, 2008

[18] E. A. Long, "Classroom Lighting Design for Students with Autism Spectrum Disorder," Kansas State University, 2010.

[19] M. Kinnealey, B. Pfeiffer, J. Miller, C. Roan, R. Shoener, and M. L. Ellner, "Effect of classroom modification on attention and engagement of students with autism or dyspraxia," Am. J. Occup. Ther., vol. 66, no. 5, pp. 511-519, 2012.

[20] K. S. Gaines and Z. D. Curry, "The Inclusive Classroom: The Effects of Color on Learning and Behavior," J. Fam. Consum. Sci. Educ., vol. 29 , no. 1, pp. 46-57, 2011.

[21] F. H. Mahnke and R. H. Mahnke, Color and Light in Man-made Environments. Canada: John Wiley \& Sons, Inc., 1993. 
[22] Z. O'Connor, "Colour psychology and colour therapy: Caveat emptor," Color Res. Appl., vol. 36, no. 3, pp. 229-234, 2011.

[23] M. Mostafa, "Architecture for autism: Autism aspects TM in school design,” Int. J. Archit. Res., vol. 8, no. March 2014, pp. 143-157, 2014.
[24] H. Mcnally, D. Morris, and K. Mcallister, Experiencing Primary School through the lens of the autistic spectrum. Aldo goes to Primary School, no. January 2013. 2013.

[25] S. D. Mayes et al., "Unusual fears in children with autism," Res. Autism Spectr. Disord., vol. 7, no. 1, pp. 151-158, 2013. 